\title{
TREATMENT OF SUPRACONDYLAR FEMUR FRACTURES BY LOCKED PLATE
}

\author{
By

\section{Haitham Mahmoud Abd El-Halim Elwany, Ahmed Ibrahim Akar and Mohamed Abd El-Rahman Alnahas}

Department of Orthopedic Surgery, Faculty of Medicine, Al-Azhar University

Corresponding author: Haitham Mahmoud Abd El-Halim Elwany,

Mobile: 01550093946, E-mail: dr.haitham2015@gmail.com

\begin{abstract}
Background: Locked plates have more advantages than conventional plates especially when dealing with complex supracondylar femur fractures or osteoporotic bone.

Objective: To evaluate the supracondylar femur fractures treated by locked plates.

Patients and Methods: During the period between July 2019 and July 2020, a prospective study was conducted on twenty patients having supracondylar femur fractures and managed by surgical fixation by "locked plates". They were followed up for 6 months.

Results: The mean age of patients was 57 years, $70 \%$ of them were males and $30 \%$ were females. The cases were divided into two equal parts $50 \%$ were left sided and the other $50 \%$ were right sided. Knowing that seven patients have extra-articular fractures and thirteen patients has intra-articular fractures. The result of radiological union.8 was variable $50 \%$ of the patients achieved their radiological union in 3 months, 35\% patients in 4 months and the remaining 10\% achieved their radiological union in more than 6 months which was considered "delayed response", and only one patient did not achieve any type of union. These results reflected that $35 \%$ of patients were excellent, $25 \%$ good, $30 \%$ fair and only $10 \%$ had poor results.
\end{abstract}

Conclusion: Locked plate is a safe procedure for supracondylar femur fractures with an excellent functional outcome and both early clinical and radiological union.

Keywords: Supracondylar femur fracture, Locked plates.

\section{INTRODUCTION}

The femoral bone is the longest, heaviest and strongest bone in the body, and is essential for normal ambulation. It is almost cylindrical in the greater part of its length (Maidment et al., 2012). Supracondylar femoral fractures occur in about one-tenth the rate of proximal femoral fractures and make up to $6 \%$ of femur fractures, there is a bimodal distribution of supracondylar femur fractures based on age and sex. Most highenergy trauma supracondylar femoral fractures occur in males between age 15 and 50 years, while most low-energy trauma fractures occur in old osteoporotic women more than 50 years (Coon and Best, 2019). Supracondylar femur fractures occur in the distal femoral third, which is the area that lies between a line passing through the knee joint space and another line parallels the former one and at a distance equal to the width of the tow condyles (Zhou et al., 2019).

The AO/OTA (Orthopedic Trauma Association) is the commonest 


\section{HAITHAM MAHMOUD ABD EL-HALIM et al.,}

classification system used for supracondylar femur fractures. Supracondylar femur is number 33 in this system, and the fracture is then classified A (extra-articular), B (partial articular) and $\mathrm{C}$ (complete articular) fracture. Each type is then classified into 1,2 , or 3 based on the amount and site of fracture comminution (Rodríguez-Merchán et al., 2014).

The aim of treatment includes anatomical reduction of the knee articular surface, restoration of femur alignment, early postoperative range of motion, and early patient mobilization (Padha et al., 2016). The introduction of femur plates with locked screws has provided increase in the fixation rigidity in osteoporotic bone or in periarticular or juxta-articular fractures with a short epiphyseal segment (Kohli et al., 2016).

Compared to non-locking plates, the locking construct has a significantly higher load to failure, less permanent deformation with cyclic loading and adequate axial stiffness, but more flexibility when compared to conventional fixed-angle implants which have a high rate of distal cut-out from the two femoral condyles (Cornell and Ayalon, 2011). Distal femoral locking plates are anatomically contoured and have multiple locking screw options distally to allow for secure fixation in the typical short condylar segment (Hou et al., 2012). The distal femoral locking compression plate allows for bicortical locking screws as well as the ability to place compression and locking screws in the same plate (Gouda, 2015 and Mahmoud and Salah, 2015).
The present work aimed to evaluate the of supracondylar femoral fractures treated by locked plates.

\section{PATIENTS AND METHODS}

This prospective study included twenty patients having supracondylar femur fractures managed with surgical fixation by locked plate at the Department of Orthopedic Surgery Gamal Abdel Nasser Health Insurance Hospital, during the period between May 2019 and May 2020. Last patient follow up period for 6 months, ended before the end of the study period. The period of follow up of the cases was 6-12 months. The fractures were classified using AO/OTA fracture classification, and type $\mathrm{A}$ and $\mathrm{C}$ were considered in this study. Skeletally immature patients, limitation in lower extremity functions and AO/OTA Type B fractures were excluded.

All patients in this study were clinically assisted. Radiographic examinations including plain X-ray antero-posterior and lateral views of the femur, knee and hip joints and CT scan in complex multiplane fractures were done to determine the fracture type; any associated other fractures and Grade of osteoporosis.

Prophylactic preoperative I.V antibiotic (3rd generation cephalosporin $2 \mathrm{gm}$ ) was used 30 minutes before surgery.

The standard lateral approach was used, and the site of the joint was determined with $\mathrm{K}$. wires. The plate on the lateral condyle and a guide wire were placed to secure the plate position on the condyle using $\mathrm{C}$-arm imaging. Locking screws were then inserted. After inserting 
all distal screws, C-arm was used to confirm positioning.

Metaphyseal diaphyseal reduction with manual traction was done to reduce length and rotation and facilitate Varus/valgus reduction. The plate was then secured to the bone using convential screws to obtain compression and alignment, and then locked screws were placed.

Closure in layers over a suction drain and sterile dressing was applied.

Post-operatively I.V antibiotics (3rd generation cephalosporin $1 \mathrm{gm}$ two times daily) were taken for 2 days and then shifted to oral antibiotics (amoxicillin/clavulanic acid $1 \mathrm{gm}$ twice daily for 5 days). Monitoring the neurovascular status, analgesia, low molecular weight heparin and radiographs were obtained. Knee exercises starting as soon as possible. Physiotherapy was encouraged and weight bearing was restricted until radiological signs of union.

Functional assessment war done using the Schatzker scoring system (Sabarisree et al., 2017) to assess every patient at 6 months postoperatively.

Variables of each patient were recorded and analyzed with respect to age, sex, fracture type, mode of trauma, limb involvement, associated comorbidities, time lapse before surgery, occupation, BMI, and final outcome.

\section{Statistical analysis:}

Recorded data were analyzed using the statistical package for social sciences, version (15). Quantitative data were expressed as mean \pm standard deviation (SD). Qualitative data were expressed as frequency and percentage. Independentsamples t-test of significance was used when comparing between two means. Chisquare $(\mathrm{x} 2)$ test of significance was used in order to compare proportions between two qualitative parameters. The confidence interval was set to $95 \%$ and the margin of error accepted was set to $5 \%$. The p-value was considered significant which: P-value which $<0.05$.

\section{RESULTS}

Twenty patients having supracondylar femur fractures managed by surgical fixation by "locked plates" were followed up for 6-12 months. $70 \%$ of the patients were males and $30 \%$ were females. The cases were divided into two equal parts $50 \%$ were left sided and the other $50 \%$ were right sided. Knowing that seven patients have extra-articular fractures and thirteen patients has intra-articular fractures. The result of radiological union were variable $50 \%$ of the patients achieved their radiological union in 3 months, $35 \%$ patients in 4 months and the remaining $10 \%$ achieved their radiological union in more than 6 months and only one patient who didn't achieve any type of union (Table 1). 
Table (1): Distribution of the studied cases according to time of union

\begin{tabular}{|c|c|c|}
\hline Time of union & No. & \% \\
\hline$\leq 3$ & 10 & 50 \\
$3-4$ & 7 & 35 \\
$>4$ & 2 & 10 \\
Non union & 1 & 5 \\
\hline Range & \multicolumn{2}{|c|}{$3.45 \pm 0.79$} \\
Mean \pm SD & \multicolumn{2}{|c|}{4} \\
Median & \\
\hline
\end{tabular}

This results reflected that $30 \%$ of patients have excellent results, $25 \%$ good, $40 \%$ were fair and only $5 \%$ had poor results. The excellent results and good results were grouped together as satisfactory $55 \%$, while the fair and poor as unsatisfactory $45 \%$ (Figure 1).

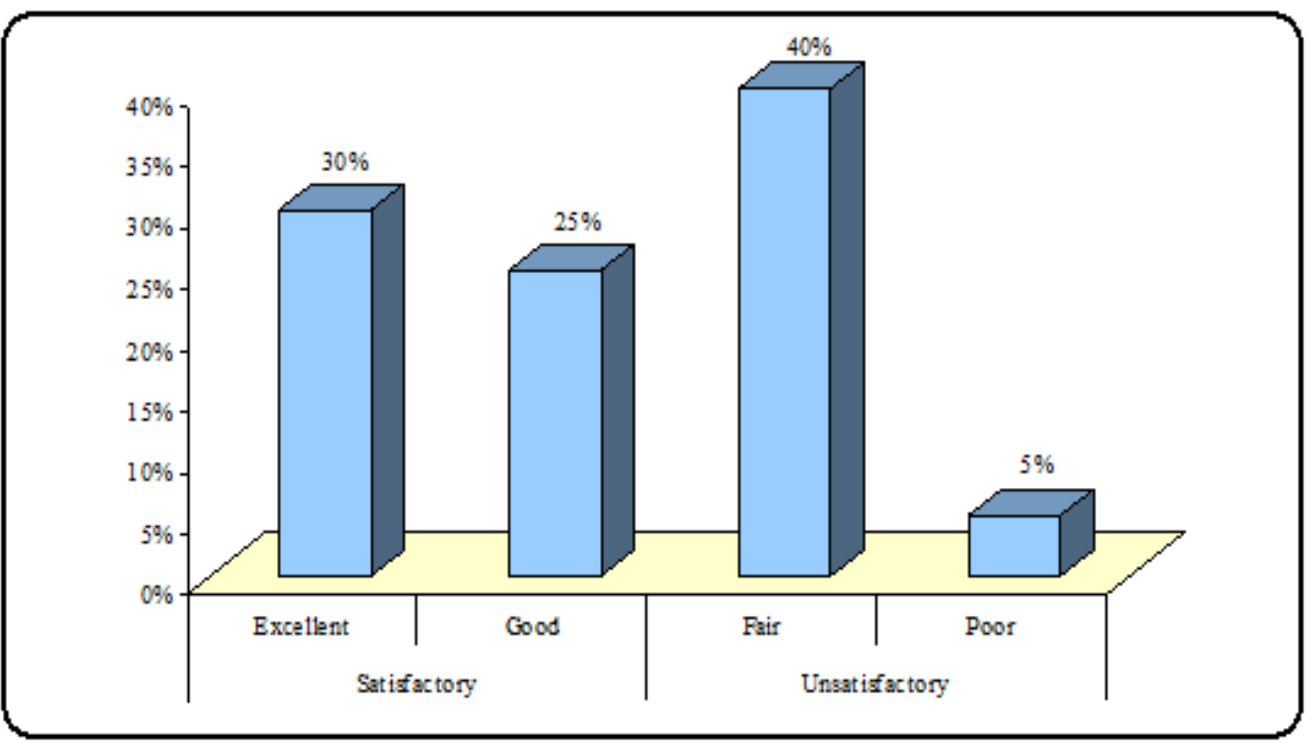

Figure (1): Distribution of the studied cases according to function outcome

Post-operative arthritis can't be evaluated because of short time of the study.

Ten patients showed more than 120 degrees flexion, nine patients between 100
-120 degrees, one patient between 90 100 degrees and no patients less than 90 degrees flexion (Table 2).

Table (2): Distribution of the studied cases according to Knee flexion

\begin{tabular}{|c|c|c|}
\hline Flexion & No & \% \\
\hline$>120$ & 10 & 50 \\
$100-120$ & 9 & 45 \\
$90-100$ & 1 & 5 \\
$<90$ & 0 & 0 \\
\hline Range & \multicolumn{2}{|c|}{$\begin{array}{c}\text { 11 } \\
\text { Mean } \pm \text { SD }\end{array}$} \\
Median & \multicolumn{2}{|c|}{$1135 \pm 12.06$} \\
\hline
\end{tabular}


Ten cases with less than $5^{\circ}$ flexion deformity, eight between $5-10^{\circ}$, one between $10-15^{\circ}$ and one case more than $15^{\circ}$ flexion deformity.

There were $45 \%$ of the patients with less than 5 degrees angular deformity,
$45 \%$ with 5-10 degrees varus angulation. $5 \%$ with $10-15$ degrees varus angulation and one case $5 \%$ more than 15 degrees angulation. No rotational malalignment were recorded (Table 3).

Table (3): Distribution of the studied cases according to angular deformity

\begin{tabular}{|c|c|c|}
\hline Angular deformity & No & \% \\
\hline$<5$ & 10 & 50 \\
$5-10$ & 8 & 40 \\
$10-15$ & 1 & 5 \\
$>15$ & 1 & 5 \\
\hline Range & \multicolumn{2}{|c|}{$2-11$} \\
Mean \pm SD & \multicolumn{3}{|c|}{$5.7 \pm 2.69$} \\
Median & \multicolumn{3}{|c|}{6} \\
\hline
\end{tabular}

Eleven cases show less than $1 \mathrm{~cm}$ shortening, seven cases between $1-1.5 \mathrm{~cm}$ shortening, one case between $1.5-2 \mathrm{~cm}$ shortening, and one case had more than $2 \mathrm{~cm}$ shortening (Table 4).

Table (4): Distribution of the studied cases according to shortening

\begin{tabular}{|c|c|c|}
\hline Shortening & No & \% \\
\hline$<1 \mathrm{~cm}$ & 11 & 55 \\
$1-1.5 \mathrm{~cm}$ & 7 & 35 \\
$1.5-2 \mathrm{~cm}$ & 1 & 5 \\
$>2 \mathrm{~cm}$ & 1 & 5 \\
\hline Range & \multicolumn{3}{|c|}{$0.3-2.5$} \\
Mean \pm SD & \multicolumn{3}{|c|}{$0.885 \pm 0.522$} \\
Median & \multicolumn{3}{|c|}{0.7} \\
\hline
\end{tabular}

Nine cases had no pain, seven had mild pain, three had moderate pain or with fatigue and one patient developed constant pain limiting the activity.

There was statistical insignificant relation between age of the patient and final outcome. Five patients who achieved excellent results were between $25-40$ years. While two cases that achieved good results were more than 60 years.

Better results were proven with low BMI but this point was proven to be statistically insignificant One patient with BMI $>30$ and three patients with BMI $\leq 25$ achieved excellent score four patients with good score had BMI 25-30.

There was statistically insignificant relation between occupation and final outcome. Our results showed insignificant relationship between mode of trauma and final outcome. Five patients of those who had excellent score were high energy. While 3 patients that had good score were low energy trauma (Figure 2). 


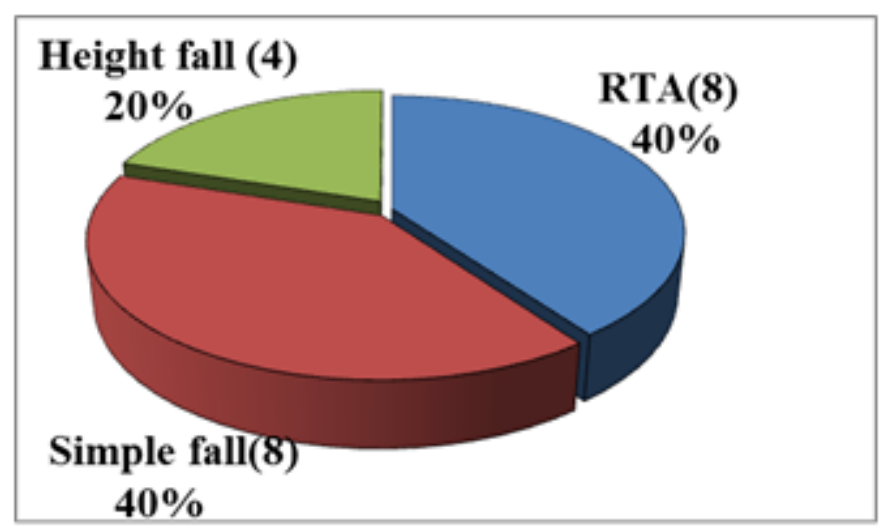

Figure (2): Distribution of the cases studied according to mechanism of trauma

Six cases who achieved excellent results had no associated comorbidity while 2 cases who achieved good results and 1 patient who achieved poor result had associated comorbidity it was proven that these relations are statistically insignificant.

Our results showed statistical insignificant relationship between time lapse before surgery and final outcome.
Seven patients had type A (extra articular) fractures while thirteen had type C (intraarticular) fractures. Four patients of those who achieved excellent scores had type C2 fractures while two patients had type C3. One patient of those who achieved good scores had type C1 fractures. There is no statistically difference between fracture classification and final outcome (Table 5).

Table (5): Relation between fracture classification and the final score

\begin{tabular}{|c|c|c|c|c|c|c|c|c|c|}
\hline $\begin{array}{l}\text { Score } \\
\text { Focture }\end{array}$ & \multicolumn{2}{|c|}{$\begin{array}{c}\text { Poor } \\
\text { (1) }\end{array}$} & \multicolumn{2}{c|}{$\begin{array}{c}\text { Fair } \\
(8)\end{array}$} & \multicolumn{2}{c|}{ Good (5) } & \multicolumn{2}{|c|}{ Excellent (6) } & $\begin{array}{c}\text { P- } \\
\text { value* }\end{array}$ \\
\hline & No. & \% & No. & \% & No. & \% & No. & \% & \\
\cline { 2 - 10 } A1 & 0 & 0 & 0 & 0 & 1 & 20 & 0 & 0 & \\
A2 & 0 & 0 & 1 & 12.5 & 1 & 20 & 1 & 16.6 & \\
A3 & 0 & 0 & 2 & 25 & 0 & 0 & 1 & 16.6 & 0.308 \\
C1 & 0 & 0 & 2 & 25 & 1 & 20 & 0 & 0 & \\
C2 & 0 & 0 & 1 & 12.5 & 1 & 20 & 3 & 50 & \\
C3 & 1 & 100 & 2 & 25 & 1 & 20 & 1 & 16.6 & \\
\hline
\end{tabular}

*: Chi-square test

There was no statistically significant relation between the sex and the final outcome. Out of the fourteen male studied, five had excellent results, two had

good results and two had fair results, while out of six females studied three had good results.

\section{Complications}

One patient developed fat embolism first day postoperative and improved with treatment.

Delayed union was recorded in two patients and non-union in one patient.
Another patient developed deep wound infection which was managed by multiple debridement and irrigation over a period of 3 weeks. Superficial wound infection was detected in one patient and managed 
by debridement and proper antibiotic. There was a mechanical failure in one case which was fixed with a Short locked plate. 2 months post-operative patient had a 2nd fall at home with metal failure and re-fracture; revision surgery was done with a longer locked plate.

\section{Case Presentation}

A 25 years old male with history of fall from height sustained right distal femur fracture $\mathrm{AO}$ type $\mathrm{C} 2$ according to his plain X-ray(figure 1) and CT scan(figure 2).

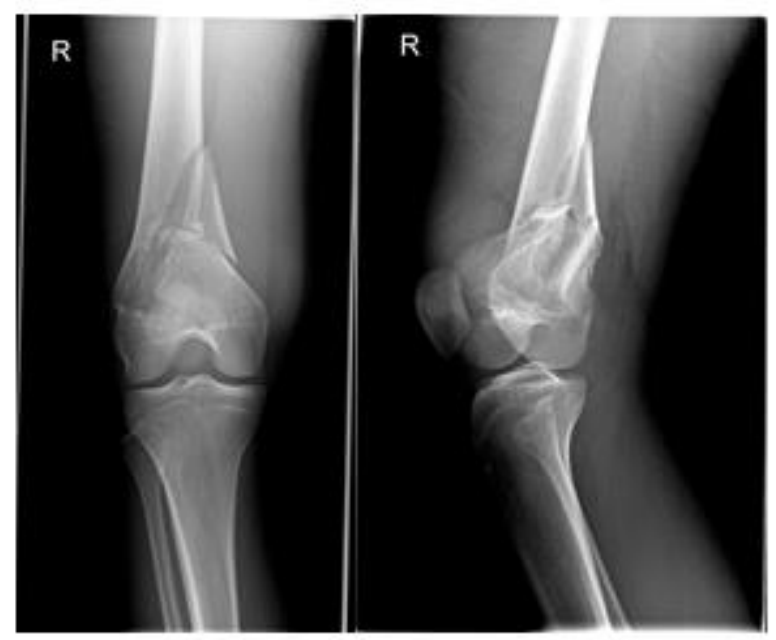

Figure (1): Pre-operative plain-x rays AP- Lateral views

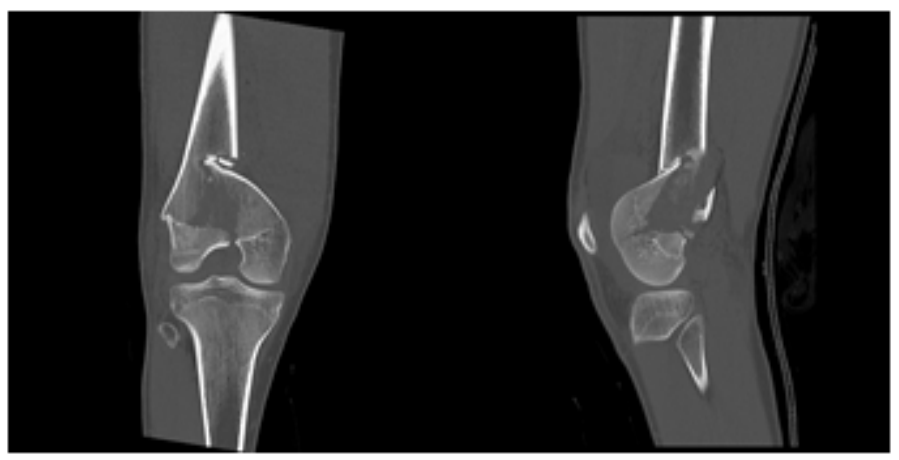

Figure (2): Pre-operative CT scan coronal and sagittal view with intra articular extension of the fracture

He was operated by locked plate upon $\quad 70$ days and started full weight bearing at 5 days after injury He achieved union in 3 months (Figure 3 ). 


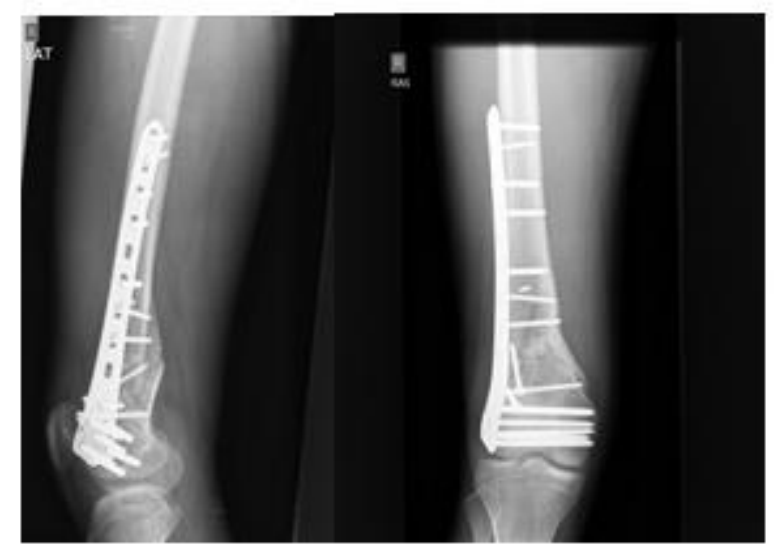

Figure (3): Plain x-ray AP and lateral views at 3 months post-operative showing callus formation

His final functional outcome score was excellent with flexion $>120$, extension lag

$<5$ degrees, No pain with walking and climbing stairs ( Figure 4).

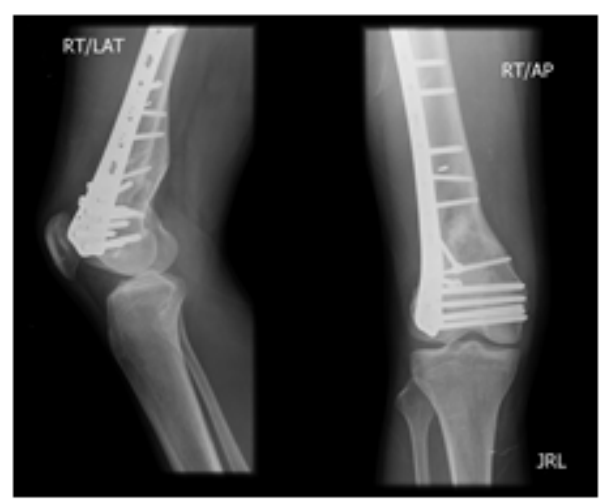

Figure (4): Plain x-ray AP and Lateral views at 6 months post operative showing complete union

\section{DISCUSSION}

Supracondylar fractures are difficult to treat as they are often unstable, comminuted, and associated with the quadriceps mechanism injury. Not only the articular but also the non-articular fracture requires anatomical reduction to restore the mechanical and the functional axis (Sahoo and Chand, 2017).

Locked plate is a single beam construct where it is fixation strength is equal to the sum of all screw-bone interfaces. Locked head screws distally have prevented Varus collapse, even in cases of osteoporosis (Vikranth et al., 2019).
Our results compared well with other series, in terms of postoperative functional scores and complication rates.

There was no statistical significant difference between our results compared with other published series (Jain et al., 2013 and Southeast Fracture Consortium, 2016).

In our study, 20 distal femoral fractures were fixed by locked plate through the standard lateral approach. The patient's ages ranged from 25 to 89 years with a mean age of 57 years. The causes of fractures were high energy trauma in twelve patients and low energy trauma in 
eight patients. The average number of days from injury to surgery was 4.5 days. Patient follow-up ranged from 6 months to 12 months.

Healing was achieved in $95 \%$ of cases with satisfactory clinical outcomes in $60 \%$ of the cases achieved excellent and good score. The average time of radiological union was 15 weeks. The average time for weight bearing in our study was 4 months. The mean knee flexion was $118.25^{\circ}$.

On comparison with the series reported by Jain et al. (2013) of cases with distal femoral fracture were fixed with locked plate, all fractures, except one united. The mean union time was 15.2 weeks. The average Knee Society scores of the patients were 82.66 (excellent), and 77.77 (good).

A comparative retrospective study of postoperative complications rates for open and closed distal femoral fractures of which $54.6 \%$ were repaired with a LISS plate and $45.4 \%$ were repaired with a locked plate, It was found no difference between LISS and locked plate in infection, plate failure, or nonunion. A Multivariate analysis revealed only open fractures to be a risk factor for nonunion and infection, regardless of device used (Southeast Fracture Consortium, 2016).

As regards the factors that may affect the final outcome. The results of our study showed that the younger the age of the patients the better were the results. However the relation between the age and the final score was statistically insignificant.

As regards the mechanism of trauma, 5 out of 12 of the high energy fractures achieved excellent outcomes while 1 out of 8 of the low energy fractures achieved excellent outcomes which can probably be attributed to the older age group and the poor bone quality of the low energy patients.

Our resulted revealed no statistically significant relationships between the patients' age, mechanism of trauma, BMI, time lapse before surgery, the presence of associated medical condition, the fracture classification and the final outcome.

\section{CONCLUSION AND RECOMMENDATION}

The distal femoral locked plate used with appropriate surgical principles provides adequate fracture fixation, permits early mobilization and high union rate. Long term studies with more heterogeneous sample sizes are recommended to prove definitively acceptable outcomes.

\section{Author Contribution:}

Authors contributed equally in the study.

\section{Conflict of Interest:}

The authors declare that they have no conflict of interest.

\section{REFERENCES}

1. Coon, M. S. and Best, B. J. (2020): Distal Femur Fractures. Treasure Island (FL): StatPearls Publishing. Available from: https://www.ncbi.nlm.nih.gov/books/NBK55 1675/. [Accessed in: July, 2020].

2. Cornell CN and Ayalon O. (2011): Evidence for success with locking plates for fragility fractures. Musculoskeletal jourNal of Hospital for SPECIAL Surgery, 7(2): 164169.

3. Gouda AEBH. (2015): Locked compression plate for the treatment of periprosthetic femoral fractures above a total knee 


\section{HAITHAM MAHMOUD ABD EL-HALIM et al.,}

arthroplasty. The Egyptian Orthopaedic Journal, 50(1): 1-7.

4. Hou Z, Bowen TR, Irgit K, Strohecker K, Matzko ME, Widmaier, J and Smith WR. (2012): Locked plating of periprosthetic femur fractures above total knee arthroplasty. Journal of Orthopaedic Trauma, 26(7): 427 432.

5. Jain JK, Asif N, Ahmad S, Qureshi O, Siddiqui YS and Rana A. (2013): Locked compression plating for peri- and intraarticular fractures around the knee. Orthopaedic Surgery, 5(4): 255-260.

6. Kohli, S., Chauhan, S., Vishwakarma, N. and Salgotra, K. (2016): Functional and radiological outcomes of distal femur intra articular fractures treated with locking compression plate. International Journal of Orthopaedics Sciences, 2: 17-21.

7. Kohn, M. D., Sassoon, A. A. andFernando, N. D. (2016): Classifications in Brief: Kellgren-Lawrence Classification of Osteoarthritis. Clinical Orthopaedics and Related Research, 474(8), 1886-189.3

8. Mahmoud TA and Salah MM. (2015): Evaluation of the results of internal fixation of comminuted osteoporotic distal femur fractures with locked plates. The Egyptian Orthopaedic Journal, 50(3): 201-207.

9. Maidment SC, Linton DH, Upchurch $\mathbf{P}$ and Barrett PM. (2012): Limb-bone scaling indicates diverse stance and gait in quadrupedal ornithischian dinosaurs. PloS one, 7(5): e36904.

10. Padha K, Singh $S$ and Ghani A (2016): Distal femur fractures and its treatment with distal femur locking plate. JK Science, 18: 76-80.
11. Rodríguez-Merchán, C. A., Gomezcardero, P. andMartinez- Lloreda, A. (2014): Complex fractures of the distal femur. In E. Rodríguez-Merchá \& J. C. Rubio-Suárez (Eds.), Complex Fractures of the Limbs: Diagnosis and Management (p.p. 61-76Cham, Switzerland: Springer AG.

12. Sabarisree, M., Jyothiprasanth, M., Babu, S. andSunku, N. (2017): A Study on Functional Outcome of Comminuted Supracondylar Fracture Femur Treated by Plating with Fibular Bone Grafting. Journal of Bone Reports \& Recommendations, 3(1): 5 .

13. Sahoo B and Chand DK. (2017): Distal femur fracture fixation by LCP-2 year experience. International Journal of Orthopaedics Sciences, 3(1): 814-818.

14. Southeast Fracture Consortium (2016): LCP Versus LISS in the Treatment of Open and Closed Distal Femur Fractures: Does it Make a Difference? Journal of Orthopaedic Trauma, 30(6): 212-216.

15. Vikranth $P$, Chaitanya $V$ and Varenya NV. (2019): Management of distal femoral fractures treated with locking compression plate: a prospective study. International Journal of Research in Orthopaedics, 5(3): 478-484.

16. Zhou Y, Pan Y, Wang Q, Hou Z and Chen W. (2019): Hoffa fracture of the femoral condyle: Injury mechanism, classification, diagnosis, and treatment. Medicine, 98(8): e14633. 


\section{علاج كسور أعلى لقمتى عظمة الفخذ بواسطة شريحة ذاتية الغلق}

هيثم محمود عبد الحليم علوانى , احمد ابراهيم عكر , محمد عبد الرحمن النحاس

قسم جراحة العظام، كلية الطب، جامعة الأزهر

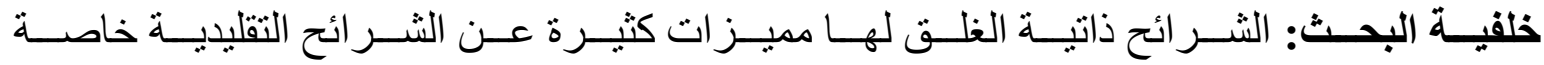
عند التعامل مع الكسور المعقدة لمنطقة فوق لقمتى عظمة الفخد.

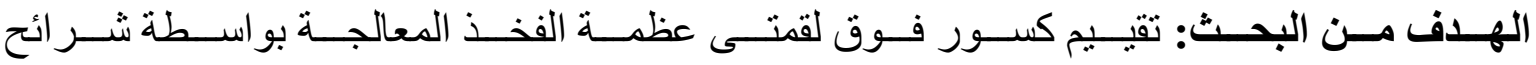
ذاتية الغلق.

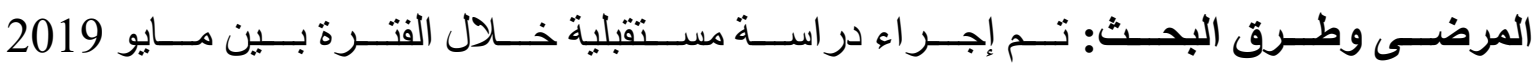

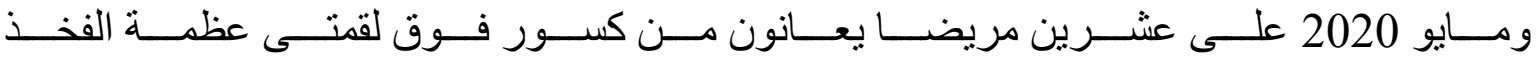

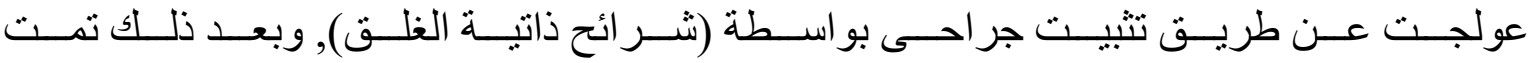

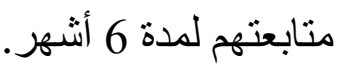

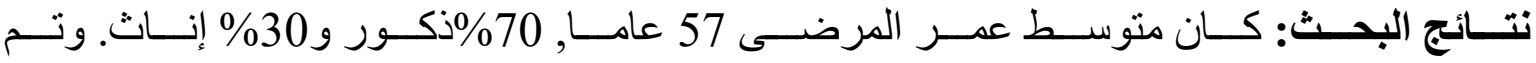

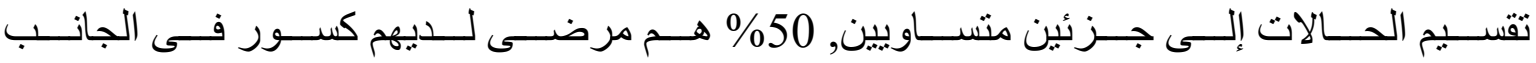

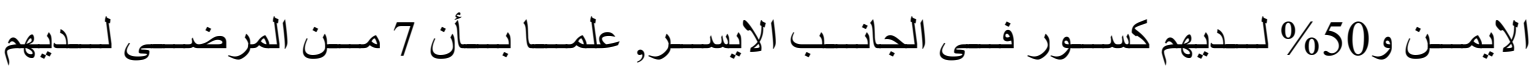

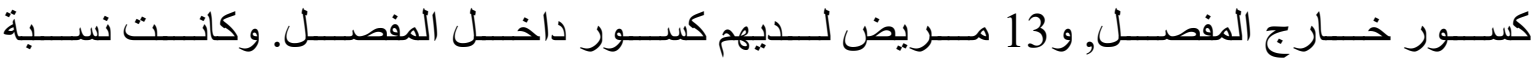

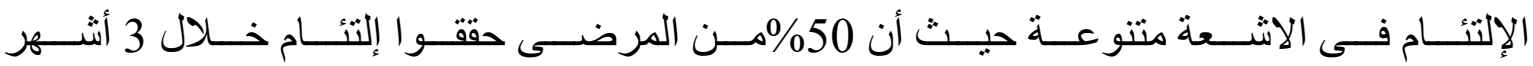

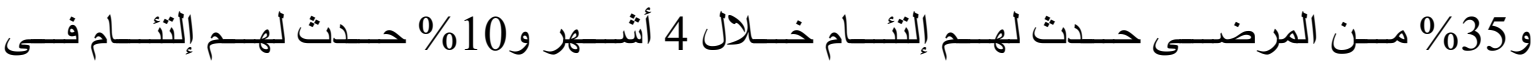

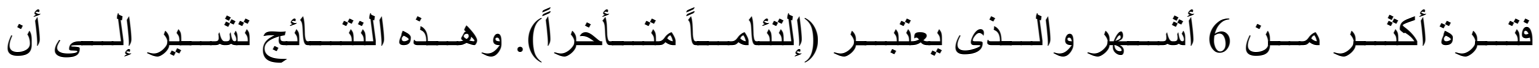

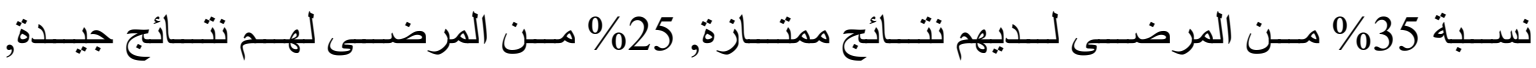

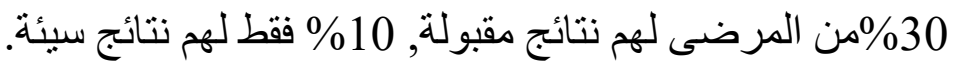

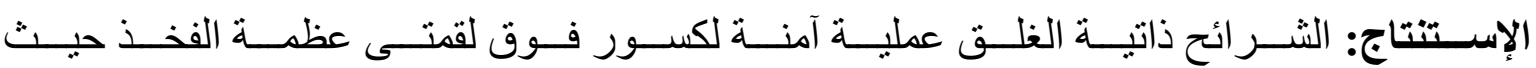
لها نتاج وظيفى ممناز و إلتئام إنشعاعى و إكلينيكى مبكر. 